\title{
Design of robust intelligent protection technique for large-scale grid-connected wind farm
}

\author{
Omar Noureldeen ${ }^{*}$ (D) and I. Hamdan
}

\begin{abstract}
This paper presents a design of robust intelligent protection technique using adaptive neuro-fuzzy inference system (ANFIS) approach to detect and classify the fault types during various faults occurrence in large-scale grid-connected wind farm. Also, it is designed to determine the fault location and isolate the wind turbine generators located in the faulted zone during fault occurrence and reconnect them after fault clearance. The studied wind farm has a total rating capacity of $120 \mathrm{MW}$, where it consists of 60 doubly fed induction generator (DFIG) wind turbines each has a capacity of $2 \mathrm{MW}$. Moreover, the wind farm generators are positioned in 6 rows, where each row consists of 10 generators. The impacts of fault type, fault location, fault duration, cascaded faults, permanent fault and external grid fault on the behaviours of the generated active and reactive power are investigated. Also, the impacts of internal and external faults in cases of different transition resistances are investigated. The simulation results indicate that, the proposed ANFIS protection technique has the ability to detect, classify and determine the fault location, then isolate the faulted zones during fault occurrence and reconnect them after fault clearance. Furthermore, the wind turbines generators which are located in un-faulted zones can stay to deliver their generated active power to the grid during fault period.
\end{abstract}

Keywords: ANFIS, Fault location, DFIG, Wind farm, Active power, Reactive power

\section{Introduction}

It is well-recognized that one way of producing electricity from renewable energy sources is to use the wind turbines that convert the wind energy contained in the flowing air into the electrical energy. Moreover, the importance of this field is one of the best ways to protect the environment by reducing the carbon emissions [1-7]. Thus, the trends of building largescale wind farm are essential to improve and increase the production efficiency of electricity. The wind farm has a lot of wind turbines which are connected to the electrical grid. The DFIG is one the most powerful generator in the market because it has various advantages such as variable speed and cost effective partially rated power converter [8-12]. As mentioned earlier, nowadays applicant is focused on a variable speed wind turbine.

\footnotetext{
* Correspondence: omar_noureldeen@svu.edu.eg

Electrical Engineering Department, Faculty of Engineering, South Valley University, Qena 83523, Egypt
}

The most prevalent generators in wind farm are the variable speed DFIG wind turbine [13]. Moreover, the DFIG had been widely used in the large-scale wind farm [14]. The DFIG consists of wound rotor slip-ring induction generator, where its stator windings are connected to a constant frequency electric grid, and its rotor windings are connected to the grid via bidirectional converters. These converters consist of rotor side converter (RSC) and grid side converter (GSC) [15]. The control systems of wind turbine play an important role to control and obtain the maximum energy from the available wind speed. The control systems of DFIG wind turbine are the RSC controller, the GSC controller and the pitch angle controller [16-21]. The disadvantage of DFIG is a sensitive to the faults occurrence in the grid [22, 23]. Furthermore, in case of a voltage dips nearing to the wind farm, over-current surges similar to short circuit currents will pass via stator windings, which will also flow via rotor windings due to a magnetic coupling between stator and rotor [24-26]. During this situation, need a special attention to protect the 
power electronic converters, DC-link capacitor and the DFIG windings from the dangerous effects by disconnecting the faulted zones. The high currents can destroy the wind turbine components therefore, the protection system is essential to protect and isolate the faulted zones inside large-scale wind farms.

In the literature, the protection technique for large-scale wind farm attracts the interest of researchers, where the most worrynty problem of wind farm generators is the cascading trip events caused by occurrence of different faults, which may propagate and cause isolation of all wind turbine generators over very large area [27-32].

This research focuses on avoiding trip events of all wind turbine generators during faults and proposes a robust intelligent protection technique based on artificial intelligence to trip only the faulted zone of wind farm. The applications of artificial intelligence in protection and control of power system are widely used [32-35]. The ANFIS architecture is an artificial intelligence approach that combines of a neural network system with a fuzzy logic system to achieve best performance and give suitable solutions for the studied problem [36-39].

The proposed protection technique for large-scale wind farm is performed and simulated using MATLAB/ Simulink platform based on robust intelligent ANFIS technique. The proposed protection technique is designed to detect fault occurrence, classify fault type and determine fault location. Also, the proposed technique is utilized to isolate the wind turbine generators of faulted zone to protect their components and reduce undesirable fault effects. The variations of active and reactive power for faulted and un-faulted wind turbine generators with different fault types, fault locations, fault durations, cascaded faults, permanent fault and external grid fault are investigated. Furthermore, the behaviours of wind farm generators in cases of internal and external faults having different transition resistances are investigated. This rest of this paper can be organized as follows:

Section 2 provides the description of a mathematical modelling and control systems of DFIG wind turbine. In Section 3, analyzes the design of robust intelligent protection technique for large-scale wind farm using ANFIS. A discussion of the simulation results is reported in Section 4 to indicate the performance and efficiency of the proposed technique. Section 5 briefly presents the conclusion.

\section{Mathematical modelling and control systems of DFIG wind turbine}

\subsection{Mathematical modelling}

As shown in Fig. 1, the DFIG wind turbine consists of different main components such as wind turbine rotor, gearbox, generator, power electronic converters, and

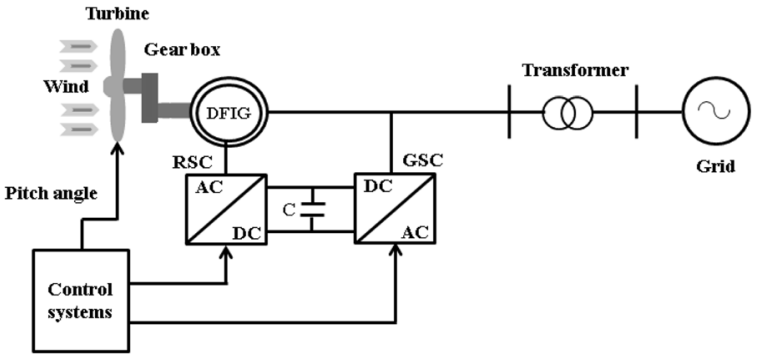

Fig. 1 Construction of DFIG wind turbine system

transformer for grid connection. The wind turbine is used to convert the wind kinetic energy into mechanical energy, where it is converted to electrical power via electrical generator. The available wind power that can be extracted from the wind is expressed as follows [40, 41]:

$$
P_{w}=0.5 \rho A V_{w}^{3}
$$

where $P_{w}$ is the wind power, $\rho$ is the air density, $A$ is the cross-sectional area of the wind crossed the blades, and $V_{w}$ is the wind speed. The developed mechanical power by the wind turbine is given by:

$$
\begin{aligned}
& P_{m}=0.5 C_{P}(\lambda, \beta) \rho A V_{w}^{3} \\
& \lambda=\frac{\omega_{r} R_{b}}{V_{w}}
\end{aligned}
$$

where $P_{m}$ represents the mechanical power, $C_{P}$ represents the power coefficient, $\lambda$ represents the tip-speed ratio, $\beta$ represents the pitch angle, $R_{b}$ represents the blade radius, and $\omega_{r}$ represents the angular speed of turbines rotor.

The wind turbine is coupled to DFIG via a gearbox, which is used to convert the low speed of wind turbine to high speed for the DFIG. The model of drive train system which contains wind turbine, low-speed shaft, high-speed shaft, and gearbox can be expressed as a two-mass model as follows [40]:

$$
\begin{aligned}
& 2 H_{t} \frac{d \omega}{d t}=T_{m}-T_{s h} \\
& 2 H_{g} \frac{d s_{r}}{d t}=-T_{s h}-T_{e m} \\
& \frac{d \theta_{s}}{d t}=\omega_{r}-\omega_{g} \\
& T_{s h}=K_{s h} \theta_{s}-D_{s h} \frac{d \theta_{s}}{d t}
\end{aligned}
$$

where $H_{t}$ and $H_{g}$ are the inertia constants of wind turbine rotor and generator rotor respectively, $\omega_{g}$ is the angular speed for a generator rotor, $T_{m}, T_{s h}$, and $T_{e m}$ are the wind torque, shaft torque, and electromagnetic torque respectively, $K_{s h}$ is the shaft stiffness coefficient, $\theta_{s}$ is the shaft tensional twist angle, and $D_{s h}$ is the damping coefficient. The 
mathematical modelling of DFIG in an appropriate $\mathrm{d}-\mathrm{q}$ frame is given as follows $[13,17]$ :

$$
\begin{aligned}
& v_{d s}=R_{s} i_{d s}-\omega_{s} \psi_{q s}+\frac{d \psi_{d s}}{d t} \\
& v_{q s}=R_{s} i_{q s}+\omega_{s} \psi_{d s}+\frac{d \psi_{q s}}{d t} \\
& v_{d r}=R_{r} i_{d r}-\omega_{r} \psi_{q r}+\frac{d \psi_{d r}}{d t} \\
& v_{q r}=R_{r} i_{q r}+\omega_{r} \psi_{d r}+\frac{d \psi_{q r}}{d t} \\
& \psi_{q s}=L_{s} i_{q s}+L_{m} i_{q r} \\
& \psi_{d s}=L_{s} i_{d s}+L_{m} i_{d r} \\
& \psi_{q r}=L_{r} i_{q r}+L_{m} i_{q s} \\
& \psi_{d r}=L_{r} i_{d r}+L_{m} i_{d s} \\
& L_{r}=L_{l r}+L_{m} \\
& L_{s}=L_{l s}+L_{m}
\end{aligned}
$$

The active and reactive power for the windings of stator and rotor are given as follows:

$$
\begin{aligned}
& P_{s}=v_{d s} i_{d s}+v_{q s} i_{q s} \\
& Q_{s}=v_{q s} i_{d s}-v_{d s} i_{q s} \\
& P_{r}=v_{d r} i_{d r}+v_{q r} i_{q r} \\
& Q_{r}=v_{q r} i_{d r}-v_{d r} i_{q r}
\end{aligned}
$$

So, the total output active and reactive power are expressed as follows:

$$
\begin{aligned}
& P=P_{s}+P_{r} \\
& Q=Q_{s}+Q_{r}
\end{aligned}
$$

where $v, i$, and $R$ represent voltages, currents, and resistances respectively, $\psi$ are flux linkages, and $L$ are inductances. In addition to the all used subscripts are as follows: $d$ is d-axis quantity, $q$ is q-axis quantity, $r$ is rotor quantity, $s$ is stator quantity, $m$ is mutual, and $l$ is leakage.

The stator windings of DFIG are connected to the grid, while the rotor windings are fed via $\mathrm{AC} / \mathrm{DC} / \mathrm{AC}$ converters such as RSC and GSC. In addition to the converters, DC-link capacitor is connected between them to acts as energy storage and keeps the DC voltage ripple with some little variations. The RSC works at variable frequencies depending on available wind speed and the GSC works at grid frequency. The power flow direction via converters depends on the operation mode of the electrical generator. In the super-synchronous operation mode, the stator output power and the rotor slip power are delivered into electrical grid. In the sub-synchronous operation mode, the stator of DFIG delivers power to the grid and the slip power to the rotor via the slip rings and the converters.

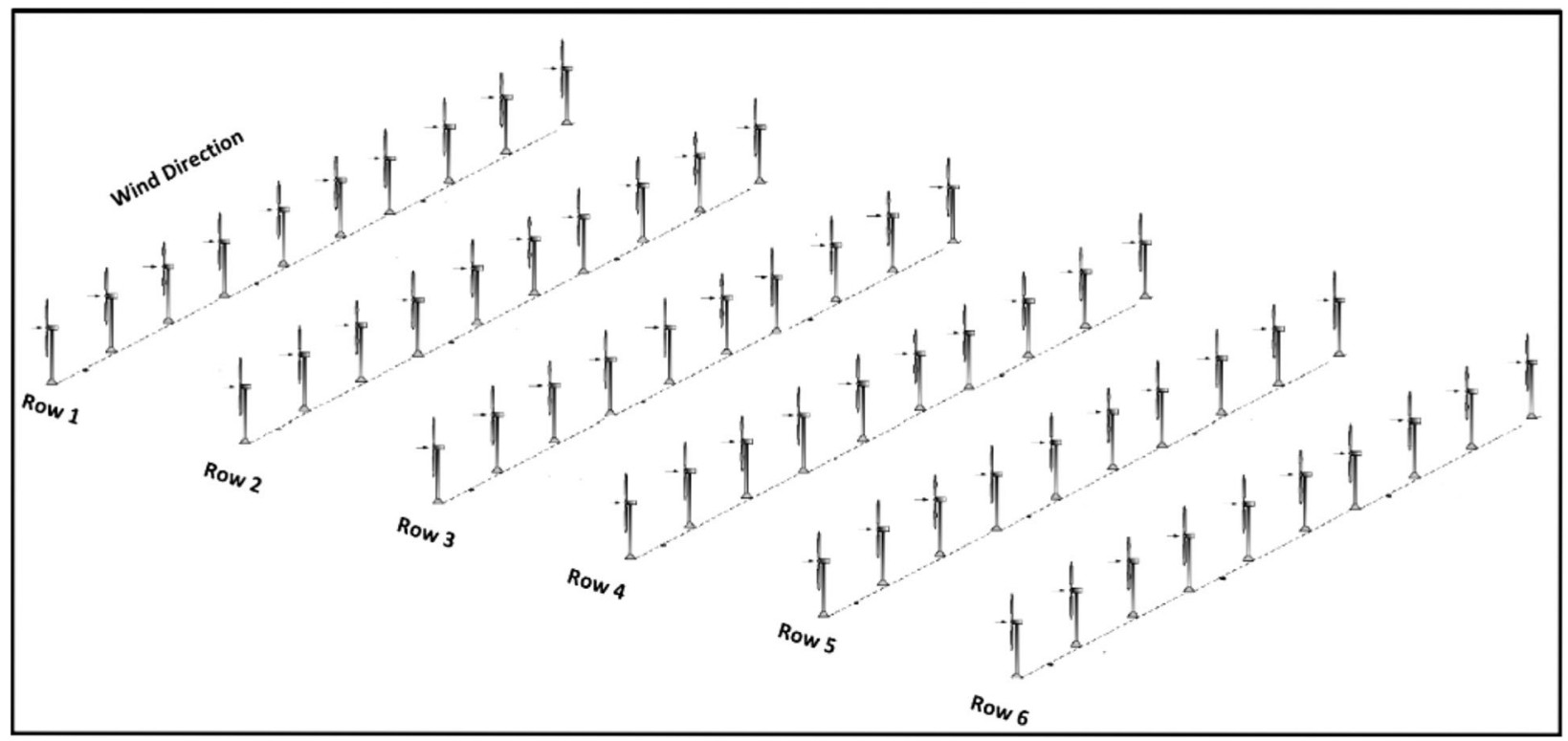

Fig. 2 Layout of the large-scale wind farm 


\subsection{Control systems}

The control system strategy of DFIG wind turbine is designed based on controlling of RSC and GSC. Also, it is designed to regulate the blades pitch angle which regulates the speed of wind turbine and protects the wind turbine mechanical parts from damage. Usually, the control systems are designed using proportional integral (PI) controller due to simple structures, clear functionality, low cost and reliable performance [42-46]. Firstly, the RSC is utilized to control active power and reactive power (or voltage level) measured at generator terminals. The control of active power is used to adjust the angular speed of turbine rotor to follow power-speed characteristic of turbine for tracking the maximum power point. The reactive current which is flowing in a converter is used to control voltage level or reactive power at the DFIG terminals. Secondly, voltage level at the DC-link capacitor is controlled using the GSC controller. Also, it can be controlled to absorb or generate reactive power for supporting the grid voltage. Thirdly, wind turbine is provided with a pitch angle control system to limit the extracted power during the condition of high wind speed. The pitch angle control system is activated only when the rotor speed increasing than the rated value due to increasing of wind speed or fault occurring.

\section{Methods}

\subsection{Studied large-scale wind farm}

The rated of studied large-scale wind farm is $120 \mathrm{MW}$, where it consists of 60 wind turbines driven by DFIG, where each wind turbine has a capacity of $2 \mathrm{MW}$. The wind turbines are positioned in regular matrix of 10 by 6 where each 10 wind turbines are located in a row as shown in Fig. 2. The wind turbines are simulated by a separated 6 generators each of them has a capacity of $20 \mathrm{MW}$ (2 MW multiplied by 10). The generated power is exported to a $220 \mathrm{kV}$ electrical grid via internal feeders and a $25 \mathrm{kV}$ transmission line has a length of $30 \mathrm{~km}$. A single line diagram of the studied wind farm connected grid is

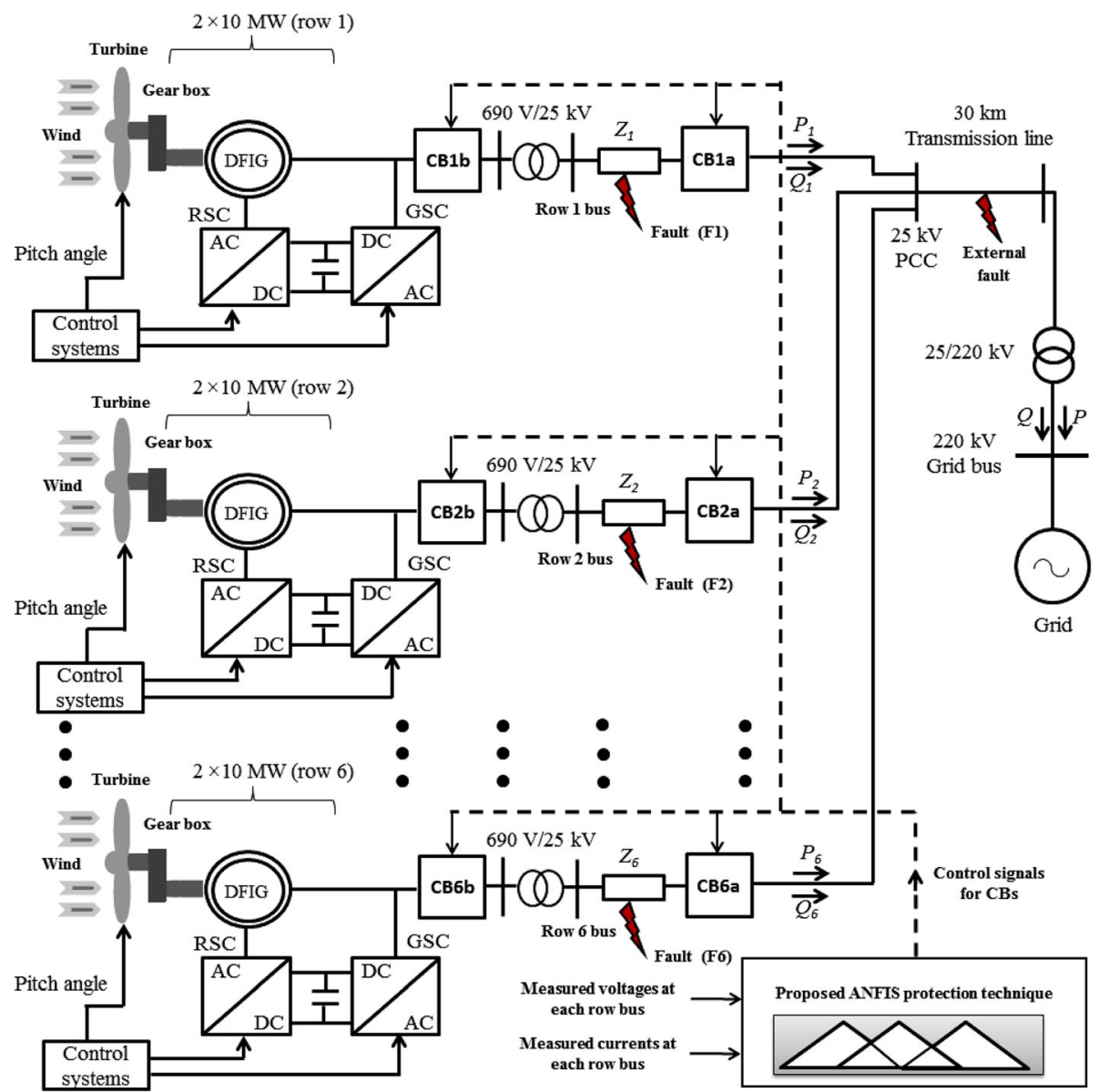

Fig. 3 Single line diagram of the studied large-scale wind farm 
illustrated in Fig. 3. Also, the main data of DFIGs, transformers, internal feeders, and transmission line are described in Table 1.

\subsection{The proposed protection technique based on ANFIS}

ANFIS is the fuzzy system represented in a framework of the adaptive networks. Moreover, ANFIS combines the concepts of fuzzy inference systems (FIS) rule base and the learning benefit of artificial neural networks (ANN) to form hybrid adaptive systems with learning capabilities. ANFIS uses FIS rule base to describe the relationship between the input/output parameters and the ANN to train the data then find best parameters for the FIS membership function to get the suitable rules. The principles of ANFIS architecture consists of five layers, namely fuzzification layer,

Table 1 Parameters of large-scale wind farm based DFIG

\begin{tabular}{|c|c|}
\hline \multicolumn{2}{|l|}{ Parameters of DFIG } \\
\hline Generator rated power (MW) & 2 \\
\hline Generator rated voltage $(\mathrm{V})$ & 690 \\
\hline Resistance of the rotor (pu) & 0.005 \\
\hline Leakage inductance of the rotor (pu) & 0.155 \\
\hline Resistance of the stator (pu) & 0.00706 \\
\hline Leakage inductance of the stator (pu) & 0.1709 \\
\hline Mutual inductance (pu) & 2.9 \\
\hline Lumped Inertia Constant (s) & 5.04 \\
\hline Frequency $(\mathrm{Hz})$ & 60 \\
\hline \multicolumn{2}{|c|}{ The parameters of the power transmission line ( $25 \mathrm{kV}$ ) } \\
\hline Zero sequence resistance $(\Omega / \mathrm{km})$ & 0.4129 \\
\hline Positive sequence resistance ( $\Omega$ /km) & 0.11529 \\
\hline Zero sequence inductance $(\mathrm{H} / \mathrm{km})$ & 0.00331 \\
\hline Positive sequence inductance $(\mathrm{H} / \mathrm{km})$ & 0.001049 \\
\hline Zero sequence capacitance (F/km) & $5.01 e-9$ \\
\hline Positive sequence capacitance ( $F / k m)$ & $11.329 \mathrm{e}-9$ \\
\hline \multicolumn{2}{|l|}{ Internal feeders $\left(Z_{1}, Z_{2}, \ldots \ldots, Z_{6}\right)$ parameters } \\
\hline Zero sequence resistance $(\Omega / \mathrm{km})$ & 0.3963 \\
\hline Positive sequence resistance $(\Omega / \mathrm{km})$ & 0.1153 \\
\hline Zero sequence inductance $(\mathrm{H} / \mathrm{km})$ & 0.00273 \\
\hline Positive sequence inductance $(\mathrm{H} / \mathrm{km})$ & 0.00105 \\
\hline \multicolumn{2}{|l|}{ Wind turbine transformer parameters } \\
\hline Voltage ratio (kV) & $0.69 / 25$ \\
\hline Resistance (pu) & 0.0081 \\
\hline Reactance (pu) & 0.0453 \\
\hline \multicolumn{2}{|l|}{ PCC bus transformer parameters } \\
\hline Voltage ratio (kV) & $25 / 220$ \\
\hline Resistance (pu) & 0.0051 \\
\hline Reactance (pu) & 0.065 \\
\hline
\end{tabular}

product rule layer, normalization layer, defuzzification layer and total summation layer. With input/output data for a given set of parameters, the membership function parameters of FIS model are adjusted using adaptive algorithm. The adaptive algorithm uses a backpropagation algorithm alone or a hybrid learning algorithm for training the parameters of MFs to emulate a given training data set where the hybrid algorithm applies a combination of the least-squares method and the backpropagation gradient descent method.

The inputs of ANFIS approach are phase voltage and phase current, which are fuzzified with membership functions and trained according to a training data measured at normal and abnormal conditions to get the best membership functions parameters. Figure 4 presents the flowchart for training and testing of ANFIS approach.

The general strategy of the proposed technique is to detect fault occurrence, classify fault type and determine the fault location of the studied wind farm based on ANFIS approach. The input signals of the proposed technique are measured magnitude values of voltages $\left(V_{a}, V_{b}, V_{c}\right)$ and currents $\left(I_{a}, I_{b}, I_{c}\right)$ at each row terminal. As shown in Fig. 5, the proposed protection technique consists of eighteen ANFIS

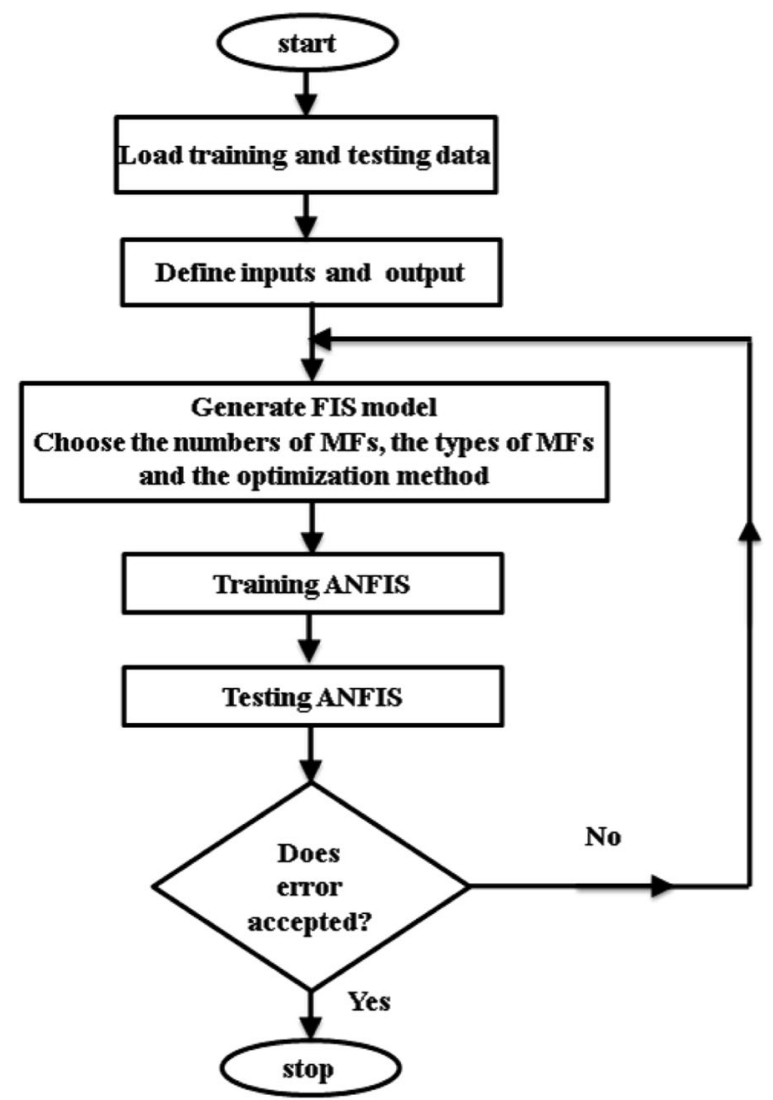

Fig. 4 Flowchart of training and testing ANFIS approach 


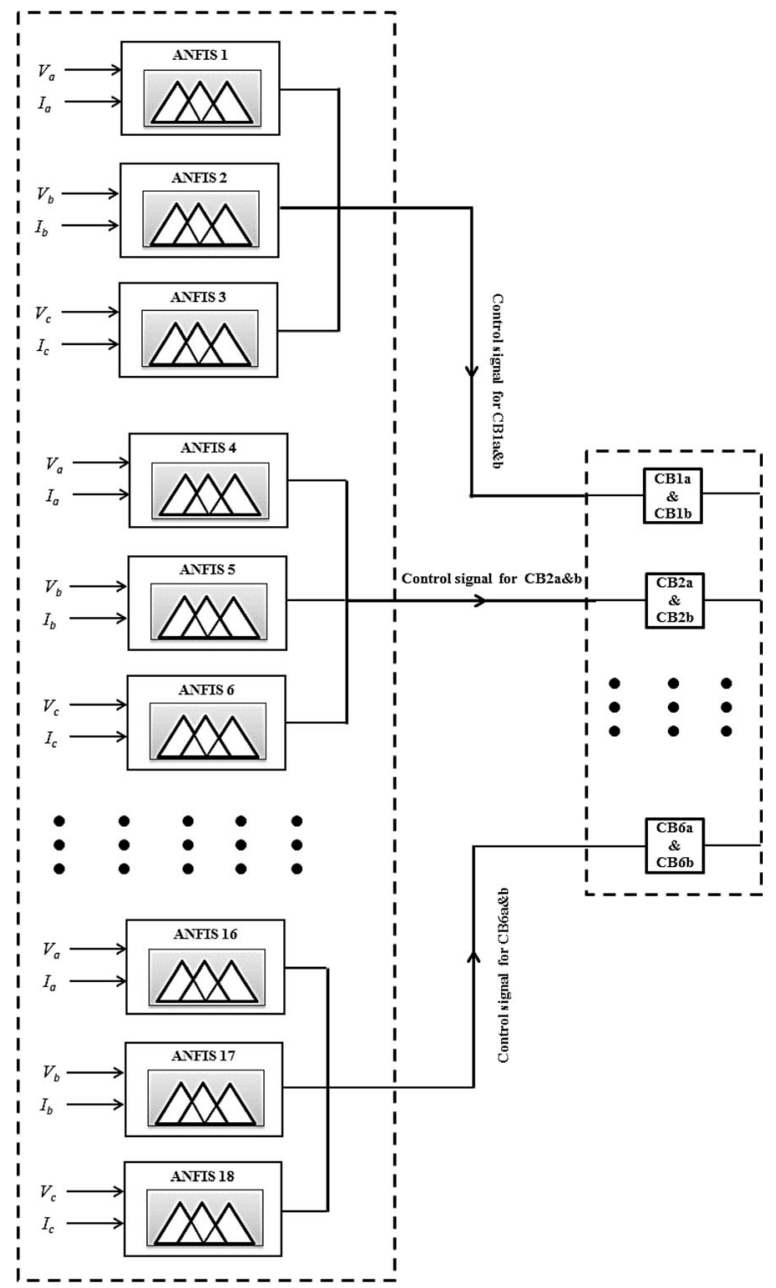

Fig. 5 Block diagram for the proposed fault protection technique based on ANFIS approach

networks dividing into six groups, where each group is responsible to protect one row using the measured values of voltages and currents at the row terminal. Each feeder of wind farm is equipped with two circuit breakers (CBs) to isolate it during fault occurrence, where the CBs are controlled by ANFIS. As illustrated in Fig. 5, the collected output of each ANFIS group is a control signal to turn off the CBs for wind turbine generators of faulted zone to isolate and protect them. During grid faults, the CBs are triggered depending on fault location and fault type to limit the high over-current and isolate the faulted row wind turbines.

The designed ANFIS networks are trained and tested using various sets of field data. The parameters of each three ANFIS structure are identical and selected as follows, two inputs and three MFs for each input, the inputs type for MF is Gaussian, the output is constant, the error tolerance is chosen to be zero, the number of epochs is 300, grid partitions, and the optimization method is hybrid algorithm. The structure and parameters of ANFIS are adjusted to perform three targets, where it can be used to detect, classify and determine the location of different faults for the studied wind farm. Figure 6 shows a flowchart of different steps for proposed protection technique.

\section{Simulation results and discussion}

In this section, the evaluation of the proposed technique and the behaviour of wind farm generators connected grid are investigated at the different fault conditions. The wind turbine generators of studied wind farm are operated at a wind speed of $12 \mathrm{~m} / \mathrm{s}$, where the total generated active power measured at the point of common coupling (PCC) bus is 108.3 MW during steady state condition. The variations of active power and reactive power at wind farm PCC bus are investigated. In the following subsections, the impacts of fault types, fault location, fault duration, cascade faults, permanent fault and external grid fault are studied. Also, the impacts of internal and external faults in cases of different transition resistances are investigated, where the value of the transition resistance is varied between $0 \Omega$ and $100 \Omega$ [47]. The accuracy of the proposed protection technique to detect fault occurrence and clearance for different fault types is investigated when these faults occur inside wind farm at row 1 for a duration time of $150 \mathrm{~ms}$. As indicated in Fig. 7, the proposed ANFIS protection technique detects the fault occurrence at instants of $150.015 \mathrm{~s}$,

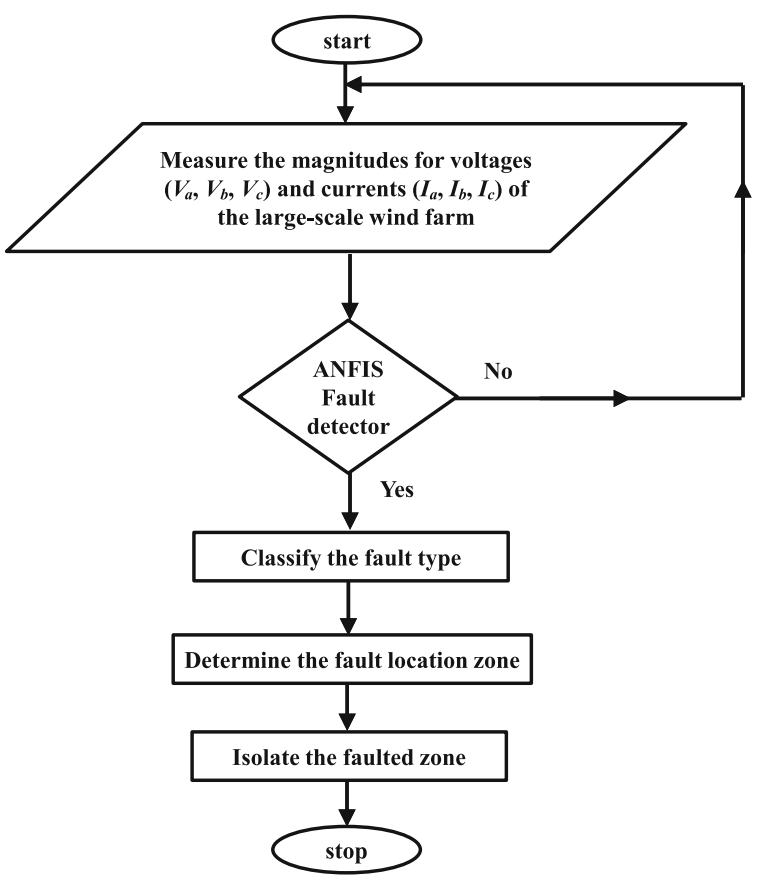

Fig. 6 Flowchart of proposed protection technique using ANFIS approach 

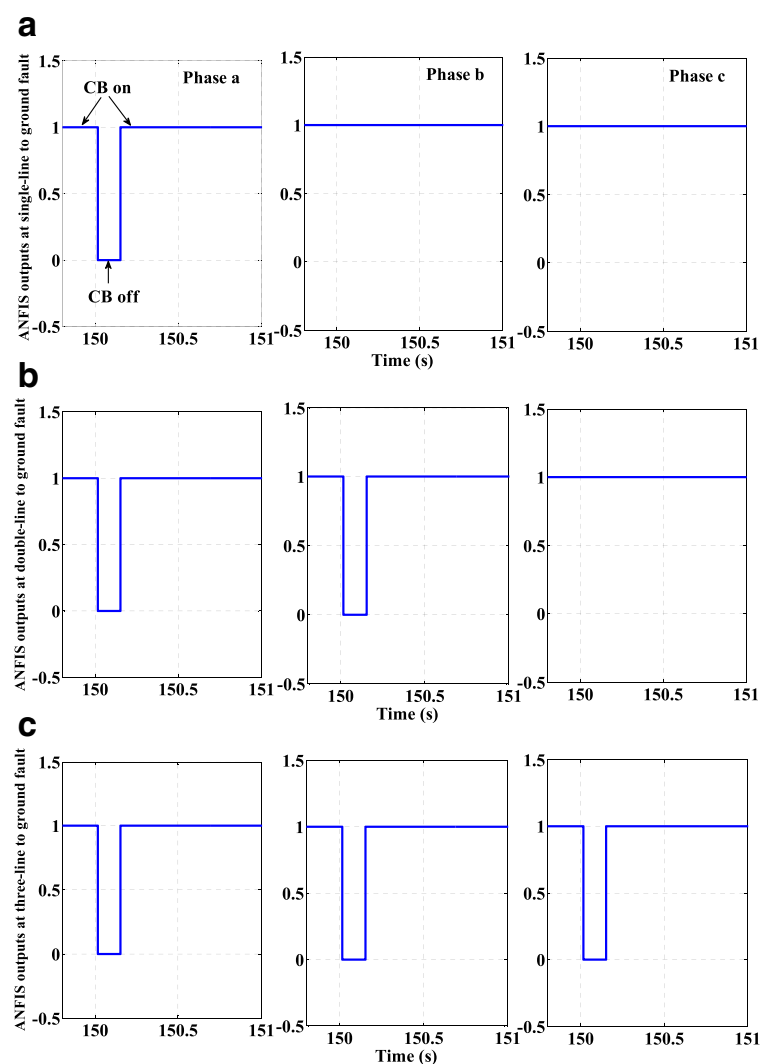

Fig. 7 ANFIS protection technique output control signals for CB at different fault types: (a) at single-line to ground fault (b) at double-line to ground fault (c) at three-line to ground fault

$150.015 \mathrm{~s}$ and $150.0153 \mathrm{~s}$ and detect the fault clearance at instants of $150.1529 \mathrm{~s}, 150.1528$ and $150.1523 \mathrm{~s}$ in cases of single-line to ground fault, double-line to ground fault and three-line to ground fault respectively.

\subsection{Impacts of fault types}

In this subsection, the behaviours of wind farm generators during occurrence of different faults such as single-line to ground fault, double-line to ground fault, and three-line to ground fault are investigated in cases of isolating and un-isolating of the faulted wind turbine generators by controlling of CBs trip signals. The studied faults are occurred close to row 1 at fault location (F1) as shown in Fig. 3.

Figure 8 shows the variations of active power, reactive power and their percentage errors at PCC bus of wind farm during occurrence of single-line to ground fault. As shown in Fig. 8a, when the faulted wind turbine generators are tripped off, the active power is fluctuated between 88.08 MW and 91.08 MW after fault occurrence, while it is fluctuated between 115.5 MW and 107.8 MW after fault clearance. On the other hand, in case of CBs not tripping of faulted wind turbine generators, there is no variation in the measured active power at PCC bus.
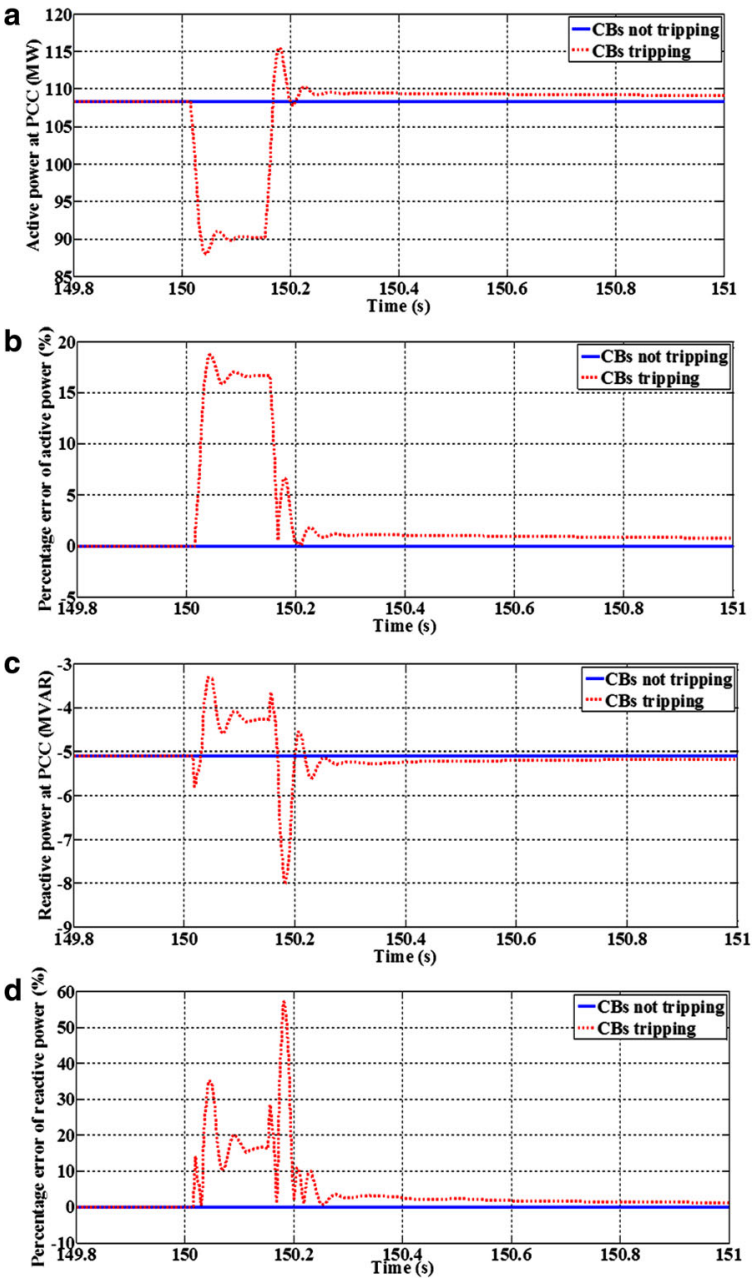

Fig. 8 Variations of active power, reactive power and percentage errors during occurrence of single-line to ground fault: (a) active power (b) percentage error of active power (c) reactive power $(\mathbf{d})$ percentage error of reactive power

The percentage errors of active power fluctuation in case of CBs tripping and not tripping are shown in Fig. 8b. Furthermore, the reactive power is fluctuated between -5.795 MVAR and-3.315 MVAR after fault occurrence, while it is fluctuated between -3.65 MVAR and - 8.019 MVAR after fault clearance in the case of CBs tripping as shown in Fig. 8c. Also, in the case of CBs not tripping, there is no variation in the measured reactive power at $\mathrm{PCC}$ bus. The percentage errors of reactive power fluctuation in case of CBs tripping and not tripping are shown in Fig. 8d.

Figure 9 shows the variations of active power, reactive power and their percentage errors at PCC bus for studied wind farm in the case of double-line to ground fault. As shown in Fig. 9a, the active power is fluctuated between 79.08 MW and 106.6 MW after fault occurrence, while it is fluctuated between 118.1 MW and 106.4 MW after fault clearance in the case of CBs tripping. Also, in 
a
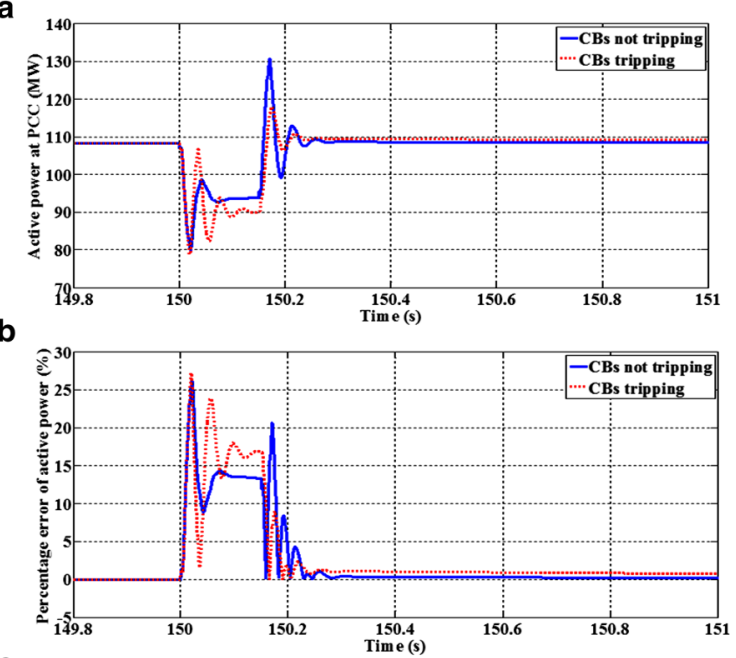

C

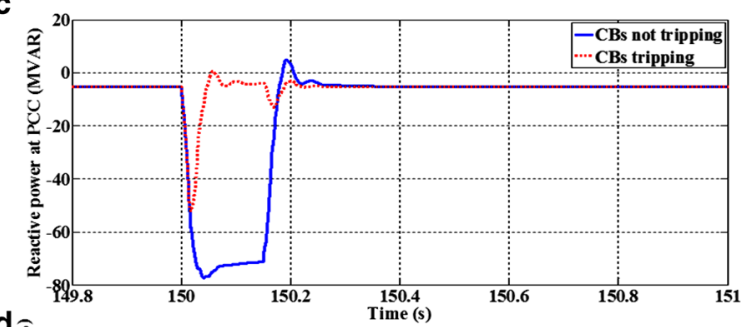

d $\widehat{a}$

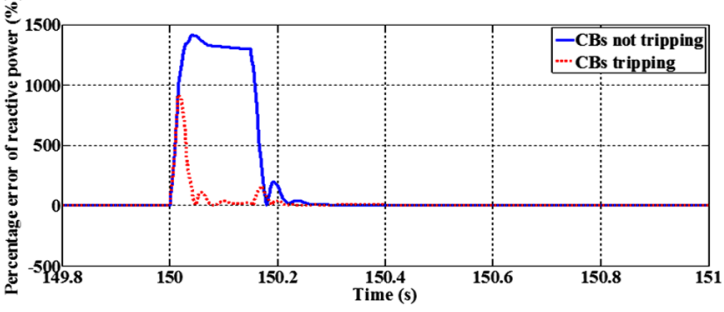

Fig. 9 Variations of active power, reactive power and percentage errors during occurrence of double-line to ground fault: (a) active power (b) percentage error of active power $(\mathbf{c})$ reactive power $(\mathbf{d})$ percentage error of reactive power

case of CBs not tripping, it is fluctuated between $80 \mathrm{MW}$ and 98.67 MW after fault occurrence, while it is fluctuated between 130.7 MW and 99.16 MW after fault clearance. The active power fluctuation percentage errors in case of CBs tripping and in case of CBs not tripping are shown in Fig. 9b. As shown in Fig. 9c, it is noticed that, the reactive power is fluctuated between - 52.1 MVAR and 0.5216 MVAR after fault occurrence, while it is fluctuated between - 13.13 MVAR and - 3.173 MVAR after fault clearance in the case of $\mathrm{CBs}$ tripping. Also, in case of $\mathrm{CBs}$ not tripping, it is decreased to - 77.35 MVAR after fault occurrence and it is increased to 4.762 MVAR after fault clearance. The reactive power fluctuation percentage errors in case of CBs tripping and not tripping are shown in Fig. 9d.
Figure 10 shows the variations of active power, reactive power and their percentage errors at PCC bus in the case of three-line to ground fault. As shown in Fig. 10a, the active power is fluctuated between 49.05 MW and $119 \mathrm{MW}$ after fault occurrence, while it is fluctuated between 115.5 MW and 105.1 MW after fault clearance in case of CBs tripping. Also, in case of CBs not tripping, it is fluctuated between 43.91 MW and 55.15 MW after fault occurrence, and it is fluctuated between $115 \mathrm{MW}$ and 76.06 MW after fault clearance. The active power fluctuation percentage errors in case of CBs tripping and in case of CBs not tripping are shown in Fig. 10b. As indicated in Fig. 10c, the reactive power is fluctuated between - 122.9 MVAR and 3.906 MVAR after fault occurrence, while it is fluctuated between -13.48 MVAR and 2.278 MVAR after fault clearance in the case of CBs not tripping. Also, in the case of CBs not

a

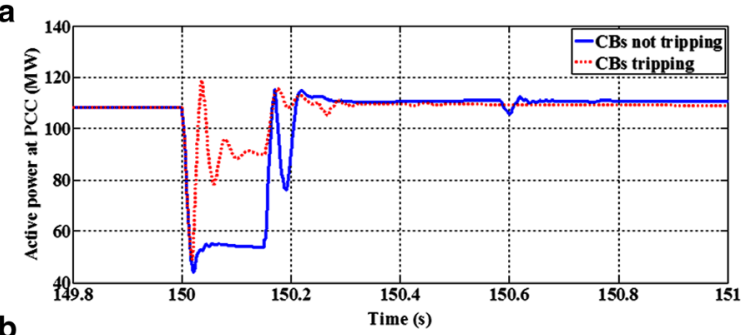

b
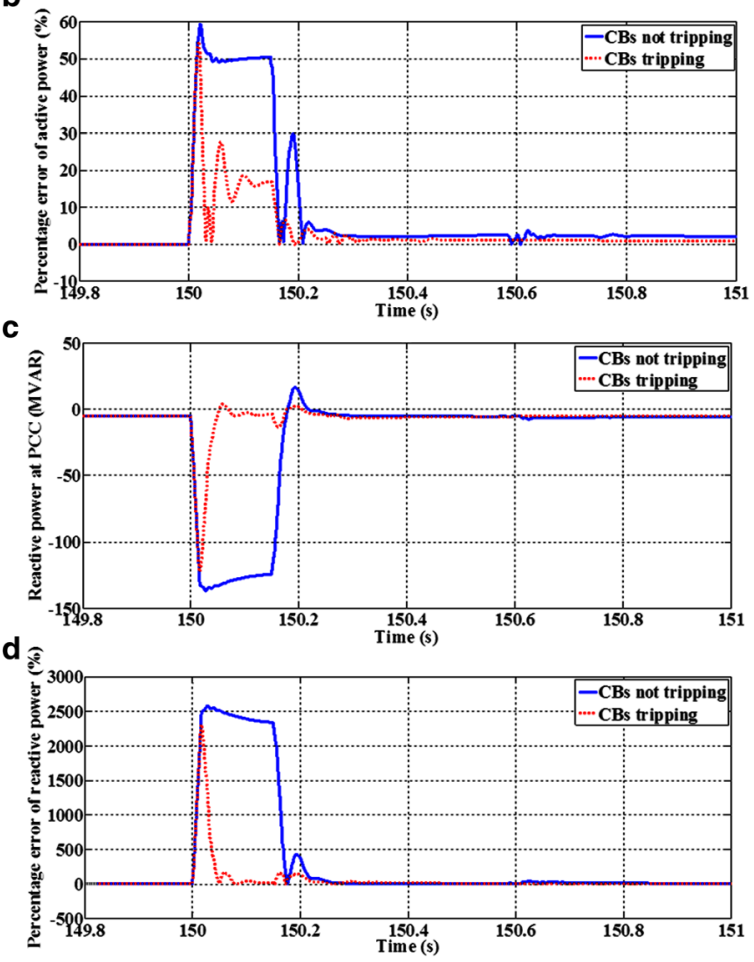

Fig. 10 Variations of active power, reactive power and percentage errors during occurrence of three-line to ground fault: (a) active power (b) percentage error of active power (c) reactive power $(\mathbf{d})$ percentage error of reactive power 
tripping, it is decreased to - 136.8 MVAR after fault occurrence and it is increased to 16.44 MVAR after fault clearance. The reactive power fluctuation percentage errors in case of $\mathrm{CBs}$ tripping and not tripping are shown in Fig. 10d.

Based on the fluctuations of active power, reactive power and their percentage errors of the studied system for different fault types, it can be suggested that, the proposed protection technique isolates the faulted wind turbine generators in cases of doubleline to ground fault and three-line to ground fault by tripping the faulted zone CBs.

\subsection{Impacts of fault locations}

To study the impacts of fault locations, the behaviour of wind farm generators is studied in case of three-line to ground fault occurs at various locations inside wind farm. The impacts of fault locations are studied for three cases, when the fault occurs at the location of F1 as first case, when the fault is occurring at the locations of F2 and F3 as second case, and when the fault occurs at the locations of F4, F5, and F6 as third case. Figure 11 shows the active power and reactive power variations at PCC bus when the fault occurs at different fault locations.

As shown in Fig. 11a, when the fault occurs at F1, the active power is fluctuated between $49.05 \mathrm{MW}$ and $119 \mathrm{MW}$ and it stabilizes at a value of $90 \mathrm{MW}$ before fault clearance. Also, it is fluctuated between 29.58 MW and 104.5 MW, then it stabilizes at the value of 71.6 MW during fault occurrence at F2 and F3, while it fluctuated between $12.65 \mathrm{MW}$ and $85.8 \mathrm{MW}$, then it stabilizes at the
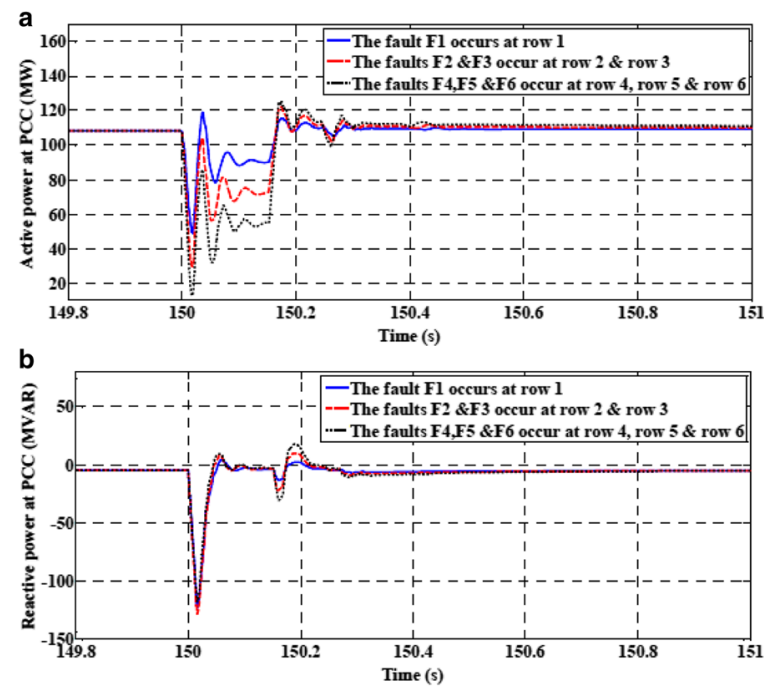

Fig. 11 Variations of active and reactive power at the PCC bus during different fault locations: (a) active power (b) reactive power value of $54.5 \mathrm{MW}$ when the fault occurs at F4, F5 and F6. The reactive power variations are indicated in Fig. 11b. It is clear that, when the fault occurs at F1, the reactive power is decreased to - 122.9 MVAR during fault period and fluctuated between - 13.48 MVAR and 2.28 MVAR after fault clearance, then returns to steady state value. When the fault occurs at F2 and F3, the reactive power is decreased to - 128.6 MVAR and fluctuated between - 21.92 MVAR and 9.88 MVAR after fault clearance. Also, it is decreased to - 117.4 MVAR when the fault occurs at the locations of F4, F5, and F6, where it is fluctuated between - 30.72 MVAR and 17.59 MVAR after fault clearance.

\subsection{Impacts of fault duration}

The impact of fault duration time on the behaviour of the studied wind farm generators is investigated in case of a three-line to ground fault occurs at row 2 for different fault duration times. The fault duration time is varied between $150 \mathrm{~ms}$ and $300 \mathrm{~ms}$, where the faults are occurring at the same instant of $150 \mathrm{~s}$ and clearing at the different instants of $150.15 \mathrm{~s}$ and $150.3 \mathrm{~s}$ of simulation time respectively. The variations of active and reactive power for different fault durations are illustrated in Fig. 12. It is obvious that, the wind farm generators return to deliver active power to the grid after fault clearance for different fault duration times.

\subsection{Impacts of cascaded faults occurrence}

In this subsection, the behaviour of wind farm generators during a composed three-line to ground faults is investigated. The composed fault is a sequence of two
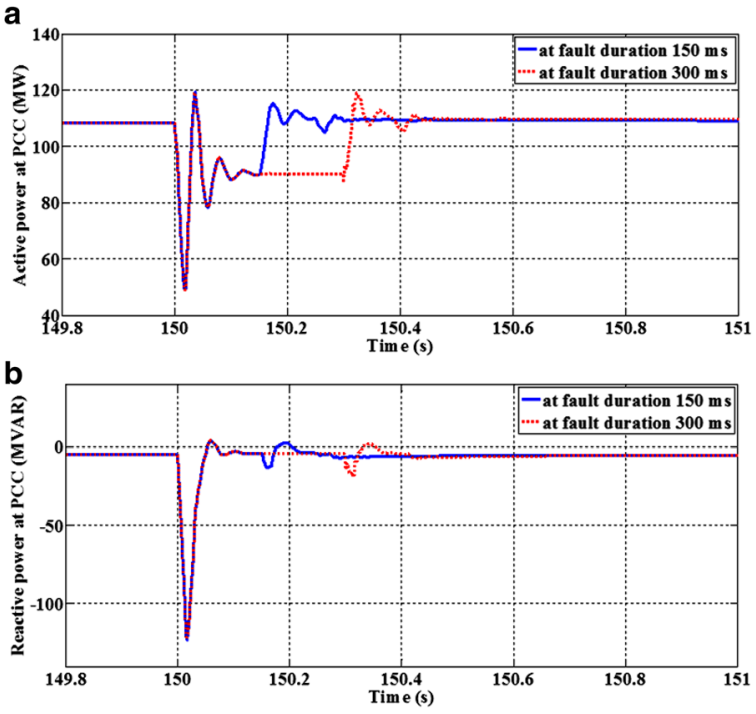

Fig. 12 Variations of active and reactive power at the PCC bus during different fault duration times: (a) active power (b) reactive power 
faults, the first fault occurs at instant of $150 \mathrm{~s}$ and clears at $150.150 \mathrm{~s}$ nearest row 1 , while the second fault occurs at the instant of $150.075 \mathrm{~s}$ and clears at $150.225 \mathrm{~s}$ nearest row 2 . In this studied case, the active and reactive power variations are monitored at PCC bus of wind farm. During fault period, the active power at PCC bus is fluctuated between $119 \mathrm{MW}$ and $36.86 \mathrm{MW}$, then returns to steady state value nearly at the instant time of $150.4 \mathrm{~s}$ after fault clearance as shown in Fig. 13a. Also, the reactive power is fluctuated between - 122.9 MVAR and 4.05 MVAR, then returns to steady state value nearly at the instant time of $150.4 \mathrm{~s}$ after fault clearance as shown in Fig. 13b.

\subsection{Impacts of permanent fault occurrence}

The behaviour of wind farm generators equipped with the proposed protection technique during permanent three-line to ground fault which it occurs at row 1 is investigated. As shown in Fig. 14a, the value of the exported power to the grid measured at PCC bus is $108.3 \mathrm{MW}$ during steady state condition. It is fluctuated between 49.05 MW and $119 \mathrm{MW}$ during fault period, where it stabilizes to $90.2 \mathrm{MW}$ nearly at the instant of $150.2 \mathrm{~s}$. The reduction of total exported active power to the grid is decreased due to the isolation of wind turbine generators for faulted row 1 by the proposed protection system technique. Also, the measured reactive power at PCC bus is - 5.1 MVAR in steady state condition. It is fluctuated between - 122.9 MVAR and 3.906 MVAR during fault period, where it stabilizes to -4.25 MVAR nearly at the instant of $150.2 \mathrm{~s}$ as shown in Fig. 14b.
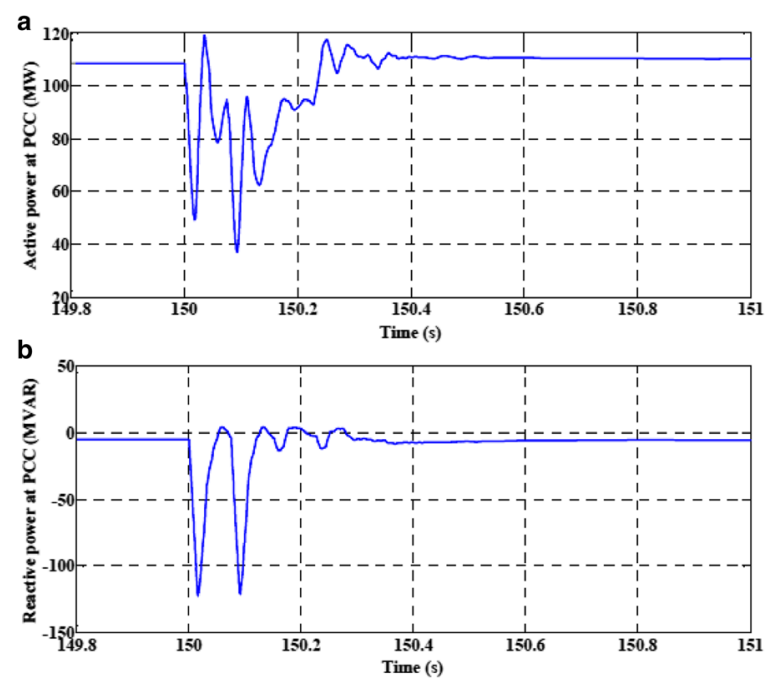

Fig. 13 Variations of active and reactive power at the PCC bus during cascaded faults occurrence: (a) active power (b) reactive power
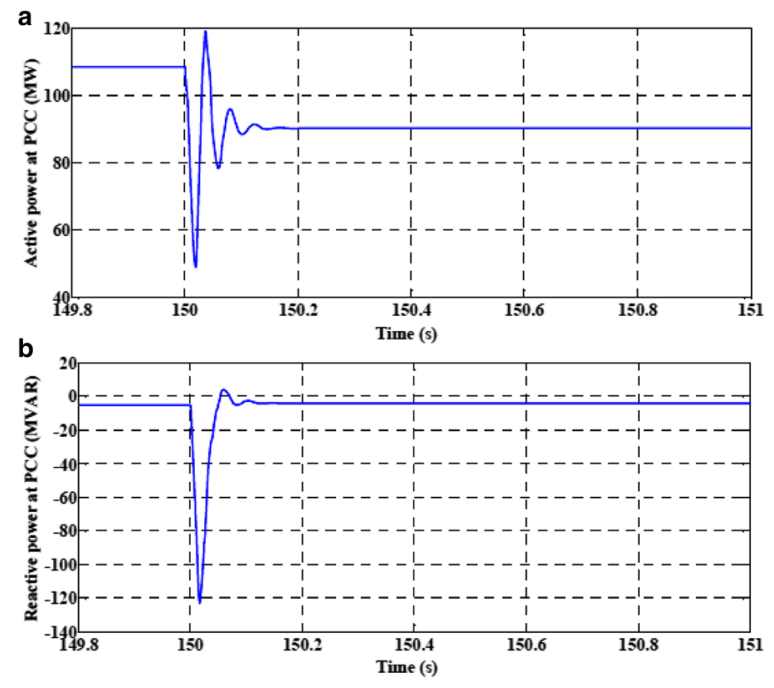

Fig. 14 Variations of active and reactive power at the PCC bus during permanent fault occurren ce: (a) active power (b) reactive power

\subsection{Impacts of external fault occurrence}

To study the impacts of external grid fault occurrence, the behaviour of wind farm generators is studied when a three-line to ground fault occurs on the transmission line at distances of $10 \mathrm{~km}$ and $30 \mathrm{~km}$ from the PCC. Figure 15 shows the impact of different external fault locations on the instants of fault detection and clearance. It is clear that, the time taken by the proposed protection technique to detect the fault occurrence or fault clearance is directly proportional to the distance between the fault location and the wind farm.

On the other hand, the active power and reactive power have more fluctuation when the fault occurs at a distance of $30 \mathrm{~km}$ comparing with the case of fault occurrence at a distance of $10 \mathrm{~km}$ as shown in Fig. 16.

\subsection{Impacts of transition resistance}

The impacts of transition resistance $\mathrm{Rg}$ on the accuracy of the proposed technique in cases of internal and external fault are studied. It is studied in case of a three-

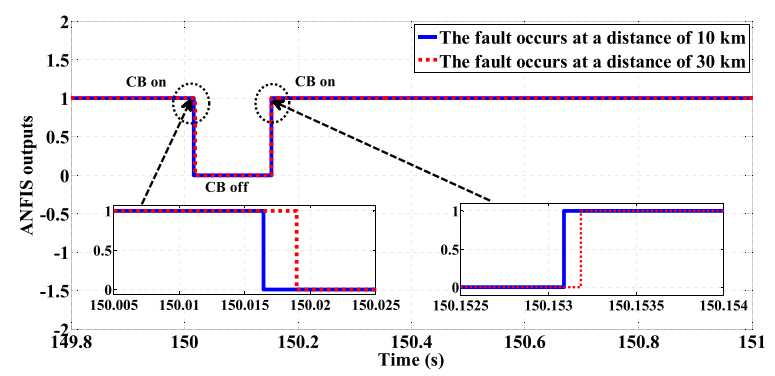

Fig. 15 ANFIS protection technique output control signal with different external fault locations 


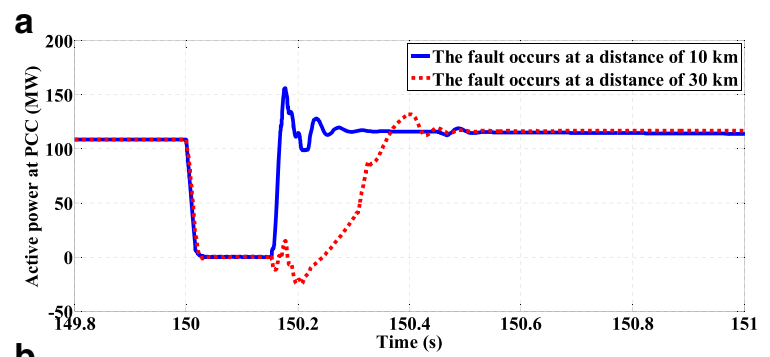

b

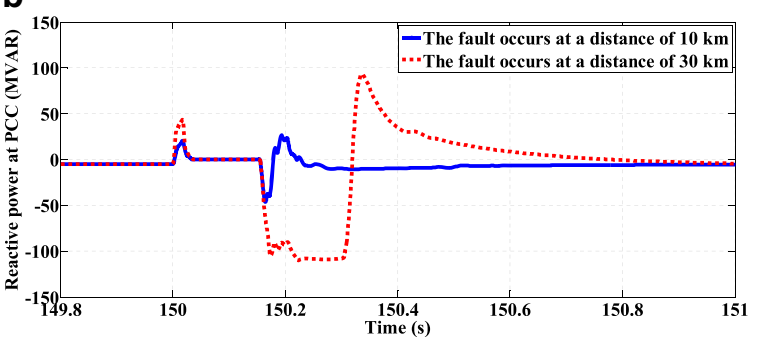

Fig. 16 Variations of active and reactive power at the PCC bus with different external fault locations: (a) active power (b) reactive power

phase to ground fault occurs at row 1 as internal fault, and when the fault occurs on the transmission line at a distance of $10 \mathrm{~km}$ from the PCC bus as external fault. The faults are studied at a different transition resistance values such as $0 \Omega, 10 \Omega$, and $100 \Omega$. The variations of the measured active and reactive power at PCC bus in case of internal and external fault are indicated in Figs. 17 and 18 respectively. It is clear that, the proposed protection technique tends to be more accurate and robust since
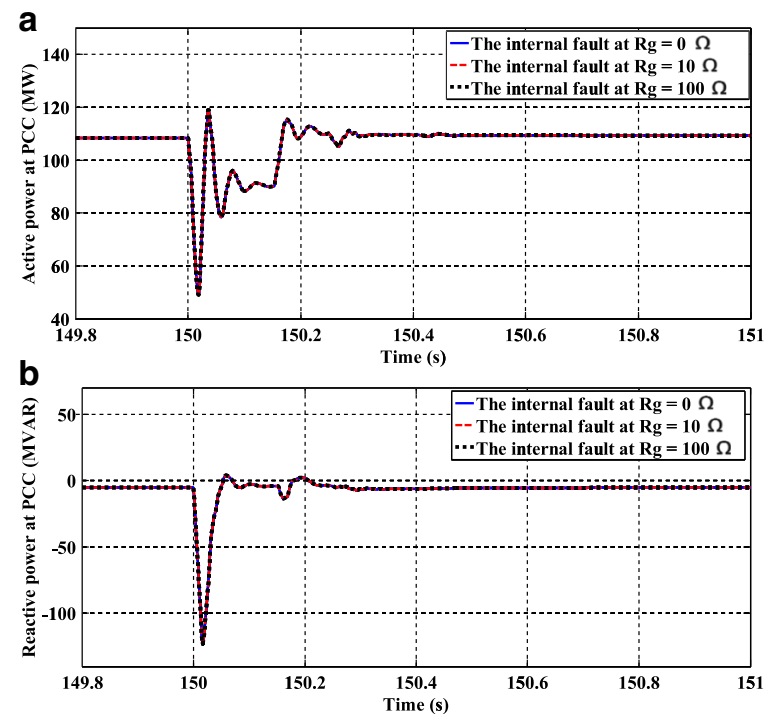

Fig. 17 Variations of active and reactive power at the PCC bus in case of internal fault with different transition resistances: (a) active power $(\mathbf{b})$ reactive power
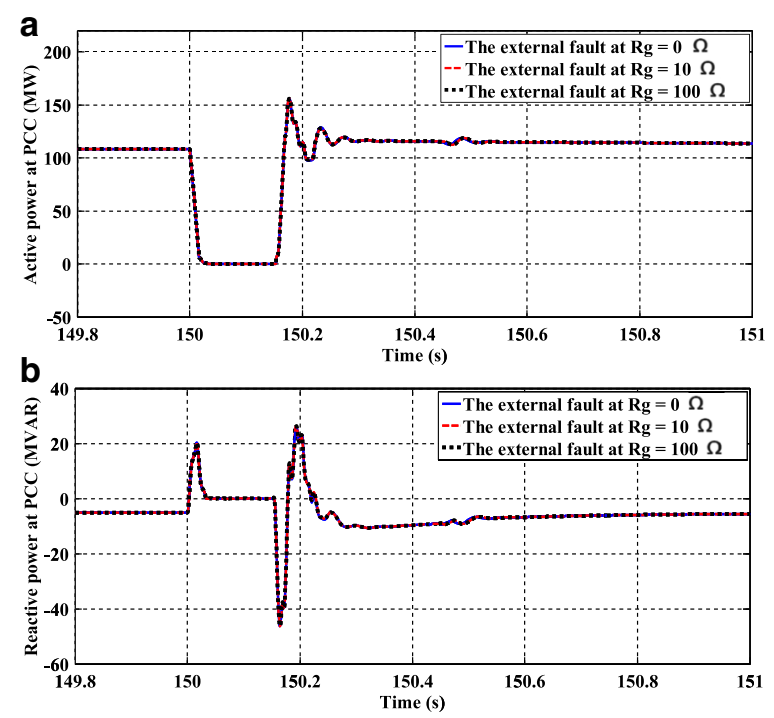

Fig. 18 Variations of active and reactive power at the PCC bus in case of external fault with different transition resistances: (a) active power $(\mathbf{b})$ reactive power

it is unaffected by the variations of transition resistance values in cases of internal and external faults.

A comparison between the proposed protection technique with others protection techniques [30-32] is provided as follows: Chen et al. [30] have presented superconducting fault current limiter (SFCL) protection system to suppress the fault current of DFIGBased wind farm. Wang et al. [31] have proposed a flexible fault ride through strategy to allow a few wind turbine generators to trip and maintains the connection to grid of most generators during fault. Noureldeen et al. [32] have proposed an efficient ANFIS crowbar protection for DFIG wind turbines to protect wind turbine generator components during grid fault. The objective of the proposed technique focuses on avoiding trip events of all wind farm during faults and proposes a robust intelligent protection technique for wind farm based on ANFIS approach to trip only the faulted wind turbine. The proposed technique has some advantages comparing with others protection techniques such as classification of fault types, determination of fault locations and isolation of faulted zones. Moreover, the proposed technique is investigated at different fault conditions such as fault duration, cascaded faults, permanent fault, and variations of transition resistance values in cases of internal and external faults.

Finally, the simulation results show that, the proposed protection technique has the ability to detect and classify the fault, hence isolate the faulted zones during fault occurrence, where that lead to support the un-faulted generators to stay in services. 


\section{Conclusion}

This paper presents a design of proposed robust intelligent protection technique for large-scale wind farm connected to electrical grid using ANFIS approach. The studied wind farm has a total rating capacity of $120 \mathrm{MW}$, where it consists of 60 DFIG wind turbines, and each generator has a capacity of $2 \mathrm{MW}$. Moreover, the wind farm generators are located in 6 rows, where each row consists of 10 generators and each row is simulated by one DFIG wind turbine with a rating of $20 \mathrm{MW}$. The proposed protection technique is designed using ANFIS approach to detect, classify and determine the location of different faults which occur in the gridconnected wind farm to protect the wind turbine generator components from dangerous effects. The proposed technique is investigated at different fault conditions such as fault types, fault location, fault duration, cascaded faults, permanent fault and external grid fault. Also, the impacts of internal and external faults in case of different transition resistances are studied. The fluctuations of active and reactive power are monitored at the PCC bus of wind farm for different fault conditions. The results show that, the measured active power for faulted row generators is fallen to zero MW due to isolation of faulted zone during fault occurrence. After fault clearance and reconnect the isolated zone, the generated active power has some fluctuation, then returns to steady state value. Also, the active power for all un-faulted rows is affected during different fault periods. The reduction of active power at PCC bus depends on the number of faulted rows and fault duration. The results show that, the proposed technique can detect, classify and determine the fault location, hence it isolates the faulted zone during fault occurrence and reconnect it after fault clearance. Also, the wind turbine generators which are located in un-faulted zones can remain in delivering their generated active power to the electrical grid. Moreover, the wind turbine generators in faulted zone return to deliver their active power to the grid after fault clearance. Finally, the simulation results demonstrate the applicability and confirm the robustness of proposed technique.

\section{Authors' contributions}

ON carried out the MATLAB model for studied wind farm. ON and IH carried out the ANFIS protection technique algorithms. ON and IH participated in result analysis and discussion. Both authors read and approved the final manuscript.

\section{Competing interests}

The authors declare that they have no competing interests.

Received: 21 December 2017 Accepted: 9 May 2018 Published online: 12 June 2018

\section{References}

1. Hameed, Z., Ahn, S. H., \& Cho, Y. M. (2010). Practical aspects of a condition monitoring system for a wind turbine with emphasis on its design, system architecture, testing and installation. Renewable Energy, 35(5), 879-894.
2. Boynuegri, A. R., Vural, B., Tascikaraoglu, A., Uzunoglu, M., \& Yumurtacı, R. (2012). Voltage regulation capability of a prototype static VAr compensator for wind applications. Applied Energy, 93, 422-431.

3. Pedro, F., Márquez, G., Mark, A., María, J., Pérez, P., \& Papaelias, M. (2012). Condition monitoring of wind turbines: Techniques and methods. Renewable Energy, 46, 169-178.

4. Evangelista, C., Valenciaga, F., \& Puleston, P. (2013). Active and reactive power control for wind turbine based on a MIMO 2-sliding mode algorithm with variable gains. IEEE Transactions on Energy Conversion, 28(3), 682-689.

5. Zhao, Y., Chai, J., \& Sun, X. (2017). Relative voltage control of the wind farms based on the local reactive power regulation. Energies, 10(281), 1-13.

6. Banshwar, A., Sharma, N. K., Sood, Y. R., \& Shrivastava, R. (2017). Optimal location and rating of wind power plants in competitive electricity market. $J$ Renew Sustain ENERGY, 9(43306), 1-14.

7. Mohamed, M. A., Eltamaly, A. M., \& Alolah, A. I. (2017). Swarm intelligencebased optimization of grid-dependent hybrid renewable energy systems. Renewable and Sustainable Energy Reviews, 77, 515-524.

8. Slootweg, J. G., De Haan, S. W. H., \& Polinder, H. (2003). General model for representing variable speed wind turbines in power system dynamics. IEEE Transactions on Power Apparatus and Systems, 18(1), 144-151.

9. Acakpovi, A., \& Ben Hagan, E. (2014). A wind turbine system model using a doubly-fed induction generator ( DFIG ). International Journal of Computers and Applications, 90(5), 6-11.

10. Chakrawarti, P., \& Jain, P. P. (2015). Performance analysis of DFIG wind turbine. International Journal of Recent Research in Electrical and Electronics Engineering, 2(1), 1-9.

11. Jamal, A., Suripto, S., \& Syahputra, R. (2016). Performance evaluation of wind turbine with doubly-fed induction generator. International Journal of Applied Engineering Research, 11(7), 4999-5004.

12. Haidar, A. M. A., Muttaqi, K. M., \& Hagh, M. T. (2017). A coordinated control approach for DC link and rotor crowbars to improve fault ride - through of DFIG based wind turbine. IEEE Transactions on Industry Applications. https:// doi.org/10.1109/TIA.2017.2686341.

13. Noureldeen, O., \& Rashad, A. (2014). Modeling and investigation of gulf ElZayt wind farm for stability studying during extreme gust wind occurrence. Ain Shams Engineering Journal, 5, 137-148.

14. Wei, Q., \& Harley, R. G. (2008). Grid connection requirements and solutions for DFIG wind turbines. In Proceedings of IEEE energy 2030 conference, Atlanta, GA, USA, 17-18 November 2008. https://doi.org/10.1109/ENERGY.2008.4781068.

15. Manonmani, N., Subbiah, V., \& Sivakumar, L. (2015). Differential evolution based IDWNN controller for fault ride-through of grid-connected doubly fed induction wind generators. Sci J, 1-15. https://doi.org/10.1155/2015/746017.

16. Demirovic, N., \& Mehinovic, N. (2014). Control systems in the wind turbines with double fed. In Proceedings of 18th international research/expert conference, Budapest, Hungary 10-12 September 2014 (pp. 253-256).

17. Behera, S., \& Singh, M. (2015). Modeling and control of dfig based wind generator. International Journal of Electrical, Electronics and Data Communication, 3(7), 67-73.

18. Justo, J. J., \& Ro, K. (2012). Control strategies of doubly fed induction generator-based wind turbine system with new rotor current protection topology. Journal of Renewable and Sustainable Energy, 4(43123), 1-14.

19. Mohd Zin, A. A. B., Pesaran, M. H. A., Khairuddin, A. B., Jahanshaloo, L., \& Shariati, O. (2013). An overview on doubly fed induction generators' controls and contributions to wind based electricity generation. Renewable and Sustainable Energy Reviews, 27, 692-708.

20. Xu, L., \& Wang, Y. (2007). Dynamic modeling and control of DFIG-based wind. IEEE Transactions on Power Apparatus and Systems, 22(1), 314-323.

21. Senjyu, T., Sakamoto, R., Urasaki, N., Funabashi, T., Fujita, H., \& Hideomi, S. (2006). Output power leveling of wind turbine generator for all operating regions by pitch angle control. IEEE Transactions on Energy Conversion, 21(2), 467-475.

22. Rahimi, M., \& Parniani, M. (2010). Efficient control scheme of wind turbines with doubly fed induction generators for low- voltage ride-through capability enhancement. IET Renewable Power Generation, 4(3), 242-252.

23. Ling, Y. (2016). The fault ride through technologies for doubly fed induction generator wind turbines. Wind Engineering, 40(1), 31-49.

24. Shi, L., Chen, N., \& Lu, Q. (2012). Dynamic characteristic analysis of doubly-fed induction generator low voltage ride-through. Energy Procedia, 16, 1526-1534.

25. Safaei, A., Vahidi, B., Hosseinian, S. H., \& Abyaneh, H. A. (2015). Fault ridethrough capability improvement of doubly fed induction generator-based 
wind turbine using static volt ampere reactive compensator. Journal of Renewable and Sustainable Energy, 7(23134), 1-14.

26. Giaourakis, D. G., \& Safacas, A. N. (2015). Effect of short-circuit faults in the back-to-back power electronic converter and rotor terminals on the operational behavior of the doubly-fed induction generator wind energy conversion system. Machine Design, 3, 2-26.

27. Tao, R., Li, F., Chen, W., Fan, Y., Liang, C., \& Li, Y. (2017). Research on the protection coordination of permanent magnet synchronous generator based wind farms with low voltage ride through capability. Protection and Control of Modern Power Systems, 2(28), 1-9.

28. Tang, Y., He, H., Wen, J., \& Liu, J. (2015). Power system stability control for a wind farm based on adaptive dynamic programming. IEEE Transactions on Smart Grid, 6(1), 166-177.

29. Ye, X., Qiao, Y., \& Lu, Z. (2012). Cascading tripping out of numerous wind turbines in China: Fault evolution analysis and simulation study. In Proceedings of IEEE PES power and energy society general meeting, 2012 (pp. 1-7).

30. Chen, L., et al. (2018). Conceptual design and performance evaluation of a 35-kV/500-a flux-coupling-type SFCL for protection of a DFIG-based wind farm. IEEE Transactions on Applied Superconductivity, 28(3). https://doi.org/10. 1109/TASC.2017.2775566.

31. Wang, S., et al. (2015). Flexible fault ride through strategy for wind farm clusters in power systems with high wind power penetration. Energy Conversion and Management, 93, 239-248.

32. Noureldeen, O., \& Hamdan, I. (2017). An efficient ANFIS crowbar protection for DFIG wind turbines during faults. In Proceedings of IEEE, nineteenth international Middle East power systems conference (MEPCON), Cairo, Egypt,19-21 December 2017 (pp. 263-269).

33. Gao, Z., Trautzsch, T. A., \& Dawson, J. G. (2002). A stable self-tuning fuzzy logic control system for industrial temperature regulation. IEEE Transactions on Industry Applications, 38(2), 414-424.

34. Wu, S., Chiang, H., Lin, H., \& Lee, T. (2005). Neural-network-based optimal fuzzy controller design for nonlinear systems. Fuzzy Sets and Systems, 154, 182-207.

35. Omar, M., Zaidan, M. A., \& Tokhi, M. O. (2011). Dynamic modelling and control of a twin-rotor system using adaptive neuro-fuzzy inference system techniques. Proceedings of the Institution of Mechanical Engineers, Part G. Journal of Aerospace Engineering, 226, 787-803.

36. Shoorehdeli, M. A., Teshnehlab, M., Sedigh, A. K., \& Khanesar, M. A. (2009). Identification using ANFIS with intelligent hybrid stable learning algorithm approaches and stability analysis of training methods. Applied Soft Computing, 9, 833-850.

37. Shoorehdeli, M. A., Teshnehlab, M., \& Sedigh, A. K. (2009). Training ANFIS as an identifier with intelligent hybrid stable learning algorithm based on particle swarm optimization and extended Kalman filter. Fuzzy Sets and Systems, 160, 922-948.

38. Bilgehan, M. (2011). Comparison of ANFIS and NN models - With a study in critical buckling load estimation. Applied Soft Computing, 11(4), 3779-3791.

39. Basser, H., et al. (2015). Hybrid ANFIS - PSO approach for predicting optimum parameters of a protective spur dike. Applied Soft Computing Journal, 30, 642-649.

40. Noureldeen, O., Rihan, M. S., \& Hasanin, B. (2011). Support of FSIG wind farm connected to the grid during faults. Journal of Engineering Science, Assiut University, 39(1), 99-111.

41. Noureldeen, O., Rihan, M., \& Hasanin, B. (2011). Stability improvement of fixed speed induction generator wind farm using STATCOM during different fault locations and durations. Ain Shams Engineering Journal, 2, 1-10.

42. Skogestad, S. (2003). Simple analytic rules for model reduction and PID controller tuning. Journal of Process Control, 13, 291-309.

43. Mudi, R. K., Dey, C., \& Lee, T. (2008). An improved auto-tuning scheme for P controllers. ISA Transactions, 47, 45-52

44. Nikita, S., Chidambaram, M., \& Chidambaram, M. (2016). Tuning of PID controllers for time delay unstable systems with two unstable poles. ScienceDirect IFAC-Papers OnLine, 49(1), 801-806.

45. Kumar, D. B. S., \& Sree, R. P. (2016). Tuning of IMC based PID controllers for integrating systems with time delay. ISA Transactions, 63, 242-255.

46. Srivastava, S., \& Pandit, V. S. (2016). A PI / PID controller for time delay systems with desired closed loop time response and guaranteed gain and phase margins. Journal of Process Control, 37, 70-77.

47. Gao, B., et al. (2014). Differential protection for an outgoing transformer of large-scale doubly fed induction generator-based wind farms. Energies, 7, 5566-5585

\section{Submit your manuscript to a SpringerOpen ${ }^{\circ}$ journal and benefit from:}

- Convenient online submission

- Rigorous peer review

- Open access: articles freely available online

- High visibility within the field

Retaining the copyright to your article

Submit your next manuscript at $>$ springeropen.com 